\title{
"Hini zum teufel mit solchen unreinen leuten!" Was ist erlaubt und was ist verboten? - Grenzen sexueller Devianz in der Chronik der Grafen von Zimmern (um 1550)
}

\begin{abstract}
"All dirty people should go to hell!" What is allowed and what is forbidden? Frontiers of sexual deviance in the Chronicle of the Counts of Zimmern (about 1550)

The article shows how sexuality is described in the Chronicle written by Count Froben Christoph of Zimmern (1519-1566). Besides many other issues there are about 200 stories concerning sex. There are sex stories of emperors and kings, followed by a series of dukes, counts and other noblemen, bishops, abbots, capitulars, monks, nuns, and priests, but Froben Christoph also tells stories of peasants, burghers, and businessmen. There is no other German chronicle and no other nobleman of this time who offers so much information about sex. The main intention of these stories firstly was simply to amuse, secondly (and rarely) to denunciate political or private enemies.

The article is not primarily interested in the degree of reality of such sex stories but rather in the way the Chronicle talks about sex. As far as this discourse is concerned, the Chronicle gives an excellent impression of what noblemen were talking about when sitting together with their fellow-noblemen. This is the focus of the following text: to present typical examples of such sex stories, and to add some reflexions concerning these examples. There are some really surprising results: Not only male but also female lust was accepted as normal and sometimes the Chronicle even approves of women who have affairs when they have "difficulties" with their husbands.
\end{abstract}

Keywords: frontiers of acceptance - Germany $16^{\text {th }}$ - century sexual behaviour

\section{Erzherzogin Mechthild - eine sexuell überaktive „fraw Venusberg"?}

Um einen Eindruck zu vermitteln, worum es in der Chronik der Grafen von Zimmern ${ }^{1}$ geht, sei

\footnotetext{
${ }^{1}$ Die einzig vollständige Ausgabe weiterhin: BARACK, Zimmerische Chronik. Die Edition von DECKERHAUfF, Chronik der Grafen von Zimmern, ist unvollständig geblieben. Zitiert wird in der Folge als ChZ nach BARACK, Zimmerische Chronik mit Band-Nr. und Seitenzahl. Vgl. zum Folgenden grundsätzlich: FRITZ, Geschichte der Sexualität 62-171; WOLF, Geschichtsschreibung 75-94, datiert die Chronik auf um
}

zu Beginn ein konkretes Beispiel genannt: Protagonistin ist Mechthild (1419-1482), geborene Pfalzgräfin bei Rhein, seit 1450 verwitwete Gräfin von Württemberg, dann Ehefrau des Bruders von Kaiser Friedrich III., des Erzherzogs Albrecht VI. (1418-1463). Albrecht, meist im Streit mit seinem kaiserlichen Bruder, hatte in diesen Jahren die vorderösterreichischen Lande inne, also die Gebiete im heutigen Gebiet der Schweiz, Baden-Württembergs und des Elsass. Mechthilds 1452 geschlossene und kinderlos gebliebene Ehe mit Albrecht existierte bald nur

1560. Vgl. auch allgemein: FRANKLIN, Die freien Herren. 
noch de jure. Das Paar traf sich nach 1455 nur noch ein einziges Mal - 1459 .

In Abwesenheit Albrechts führte Mechthild in Rottenburg am Neckar einen eigenen Hof, der sich durch Feste, Turniere, Musik und Dichtung auszeichnete. $^{2}$

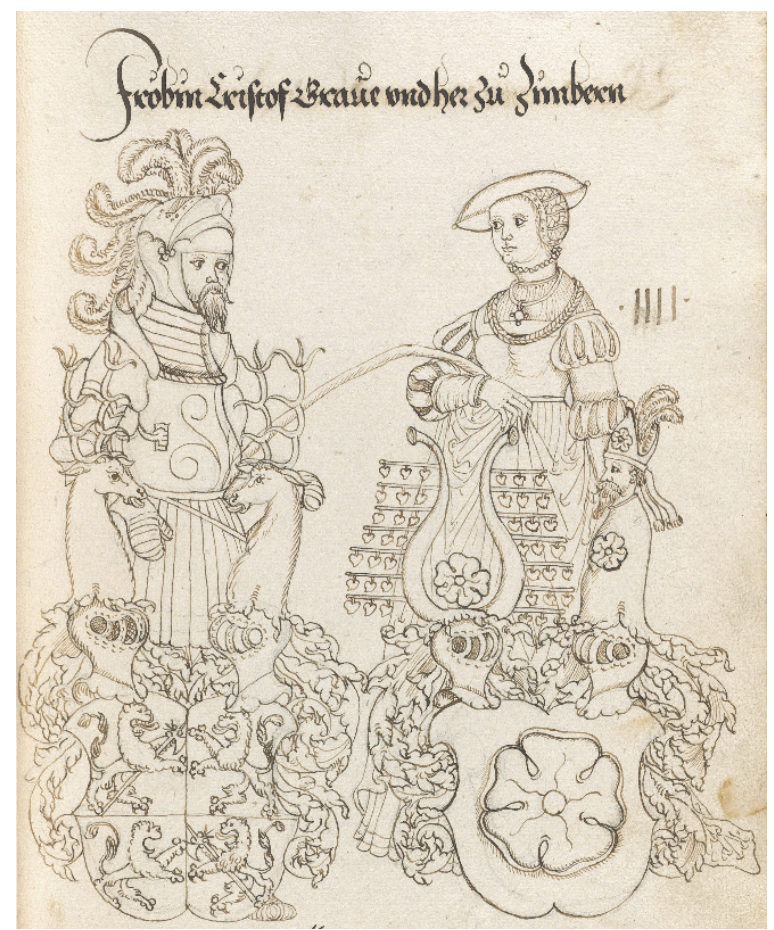

Abbildung 1: Der Chronist Froben Christoph von Zimmern und seine Gemahlin Kunigunde, Gräfin von Eberstein (Württembergische Landesbibliothek, Cod. Don. 593a, ca. 1550).

Der Chronist Froben Christoph von Zimmern (1519-1566) interessierte sich für die zu seinen Lebzeiten längst verstorbene Mechthild, weil er vermutete, sein Urgroßvater Werner sei einer von deren Liebhabern gewesen. Dazu arbeitete Froben Christoph mit den Methoden der „oral

\footnotetext{
${ }^{2}$ LANGMAIER, Albrecht VI., 418-424 sieht die Ehe als dynastisch arbeitsfähige Zweckgemeinschaft und keineswegs als gescheitert an - trotz der seit 1455 andauernden Trennung. Sogar die Kinderlosigkeit erklärt er als Resultat politischen Kalküls. Albrecht habe in seiner Situation keine Kinder brauchen können. Wenig wahrscheinlich ist das von Langmaier gezeichnete Bild eines auch außerhalb der Ehe ziemlich enthaltsamen Mannes - auch wenn Albrecht an seinen Cousin Sigmund von Tirol nicht herangekommen sein mag.
}

history" und erkundigte sich, lange bevor er die Chronik niederschrieb, „,bei den alten, die deren sachen wol gedenken mögen", wie es am Rottenburger Hof zugegangen sei. Er fand heraus, dass sein Ahn sich eher nicht „mit disem überflaischgirigen weib" eingelassen habe - und zwar deswegen, weil er wegen anderer Männer nicht zum Zuge gekommen war. Die Hofhaltung Mechthilds sei ,,aller frewden und wollusts [...] überflissig vol“" gewesen. Man hätte Mechthild "auch fraw Venusberg" nennen können. Insbesondere nach dem Tod Albrechts VI. sei Mechthild „mangierig“ gewesen und habe ihre Liebhaber nach anatomischen Kriterien ausgesucht: „Da ist kainer, er sei dann sonderlich mit aim langen und starken penicill begabt gewesen." Veit von Emershofen sei ihr Favorit gewesen: Als sie vom Fenster ihres Frauenzimmers aus einem Turnier zuschaute, habe Veit den Raum betreten, die Tür hinter sich abgeschlossen und sich von hinten Mechthild genähert. Dann „hueb er die klaider dahünden uf und fieng an dem nest zu zu schanzen“. Als die anfangs zornige Mechthild („Wer plagt mich dahinden"?) gesehen habe, dass es Veit war, habe sie ihn aufgefordert fortzufahren: "Sihe, herr Veit, seindt irs? faren für! und damit sahe sie widerum zum fenster hinauß, wie vor, und ließ herrn Veiten machen." Neben Veit werden weitere adlige Liebhaber namentlich genannt. In deren Abwesenheit habe Mechthild auch auf die Dienste ihres Ofenheizers namens Halberdrein zurückgegriffen. ${ }^{3}$

\footnotetext{
${ }^{3}$ ChZ 1, 454, dort auch: „Gnedige fraw, so E. Gnaden nackendt wer uf allen vieren stüende, und sich begebe, das ein kütt hüner derselben zwischen und durch die pain hinliefen, wie wollten sie thuen, das dero keins weder darvonen noch dahünden hinein flüege?"
} 


\section{Quelle, Stand der Forschung, Vorgehensweise}

Die drastische Darstellung Mechthilds ist eine von zahlreichen Sex-Geschichten aus der Chronik der Grafen von Zimmern. Die Chronik über das aus Südwestdeutschland stammende Geschlecht wurde um 1550 von Froben Christoph von Zimmern verfasst. Eigentlich sollte es in der Chronik um die Geschichte der Familie Froben Christophs gehen. Die Familiengeschichte wird aber häufig vermengt mit anderen Inhalten, ja oft geradezu von diesen verdrängt. Auf den etwa 2200 Seiten der Chronik kommen ungefähr 200 Geschichten vor, in denen es um Sex geht.

Diese Masse stellt für den Historiker, der bei der Erforschung der Geschichte der Sexualität des 16. Jahrhunderts oft vor der Schwierigkeit steht, nur einzelne, isolierte Funde zu haben, das gegenteilige Problem dar: Was soll man aus der Flut einschlägiger Stellen aus der Chronik eigentlich auswählen? Dazu kommen Klassifizierungsprobleme: Oft lässt sich kaum unterscheiden, was der Fantasie des Chronisten entsprang, was er aus dem Fundus kerniger Schwänke des 16. Jahrhunderts 4 übernahm oder was gesicherte historische Fakten sind. Darauf kommt es im Folgenden jedoch nicht an und deshalb ist es auch irrelevant, wenn die Forschung immer wieder zweifelt, dass und ob die sexuellen Aspekte der Mechthild-Geschichte überhaupt historisch "wahr" seien. Sogar in neueren Veröffentlichungen werden die sexuellen Aspekte der Mechthild-Darstellung in der Zimmerschen Chronik einfach ausgeblendet ${ }^{5}$ oder beiseite geredet. ${ }^{6}$ Es soll im Folgenden nicht darum ge-

\footnotetext{
${ }^{4}$ WALTER, Unkeuschheit, mit zahlreichen Beispielen von Schwänken, die sich mit Sex beschäftigen.

${ }^{5}$ MAURER, Eberhard und Mechthild; die sexuellen Aspekte um Mechthild werden gar nicht thematisiert bei Dieter MERTENS, Die württembergischen Höfe 7780 .

${ }^{6}$ Vgl. LANGMAIER, Albrecht VI.; neuestens auch MEYER, Im Schatten eines siegreichen Nachbarn? 148f.,
}

hen, in welche der drei genannten Kategorien die einzelnen Sex-Geschichten gehören (obwohl eine entsprechende Untersuchung, die bislang noch nicht geleistet wurde, bei der Einteilung in diese drei Kategorien weit mehr leisten könnte, als das bisher geschehen ist ${ }^{7}$ ).

Wichtig ist für das Folgende vielmehr, dass die Chronik vermittelt, worüber Adlige sprachen, wenn sie abends mit ihren Standesgenossen beim Wein zusammensaßen. In diesem Rahmen wird in einer Dichte wie in keiner anderen Quelle dieser Zeit deutlich, was und vor allem wie die Herren (und oft auch die anwesenden Damen) über Sex sprachen und dachten und vor allem, wo sie die Grenzen des Schicklichen und Unschicklichen zogen. Darum soll es im Folgenden vornehmlich gehen.

Die Forschung zur Zimmerschen Chronik hat weit über Mechthild hinaus - das Thema Sexualität lange Zeit ausgespart. Zu heftig war, was Froben Christoph geschrieben hat. Man wich auf andere Themen aus, zu denen die Chronik ebenfalls reichen Stoff bietet, ${ }^{8}$ oder beschränkte sich

Meyer geht über die von "sexuellen Ausschweifungen“ beherrschte Darstellung Mechthilds als „hemmungslose Nymphomanin" durch Froben Christoph beiläufig hinweg und betont die aus anderen Quellen hervorgehende Seriosität Mechthilds.

${ }^{7}$ Es wären elementare Grundsätze historischer Quellenkritik anzuwenden: Werden konkrete Namen, Personen und Sachverhalte genannt? Wie nahe liegen sie zeitlich und räumlich an der Entstehungszeit der Chronik und dem Erfahrungsbereich des Chronisten? Hier finden sich durchaus etliche plausible und nachvollziehbare Beispiele. Oder handelt es sich erkennbar um biologisch unmögliche oder unwahrscheinliche Aufschneidereien des Chronisten? Kommen dieselben Motive in identischer oder ähnlicher Form in der Schwank-Literatur oder in anderer belletristischer Literatur vor? Bieten andere Quellen - erwähnt seien als besonders reichhaltig die Akten der Pönitentiarie in Rom (vgl. dazu unten Anm. 51) - ähnliche Sachverhalte wie die Chronik?

${ }^{8}$ BADER, Die Zimmerische Chronik; BONNEKAMP, Die Zimmerische Chronik; BASTRESS-DUKEHART, The Zimmern chronicle. 
darauf, festzustellen, dass Froben Christoph eben manches allzu unschicklich ausdrücke. ${ }^{9}$ Ein 2012 erschienener Sammelband zu den Grafen von Zimmern geht etwas deutlicher, wenn auch eher am Rande, auf das sexuelle Dauerthema ein. ${ }^{10}$ Am ausführlichsten hat sich Judith J. Hurwich mit der Sexualität in der Chronik beschäftigt, allerdings unter der Fragestellung "marriage and sexuality". Sie fokussiert sich dabei auf "noble strategies" bei Heiraten oder Konkubinaten. Für die Darstellung der Sexualität im Allgemeinen interessiert sie sich nur bedingt. Da in zahlreichen Schwänken die Frauen als "untrustworthy and sexually voracious" beschrieben werden, meint sie, auch alle Geschichten in der Chronik über sexuell aktive Frauen seien nur "stereotypes of the period". ${ }^{11}$ Das mag so sein oder auch nicht. Sicher ist aber, dass all diese Geschichten erzählt wurden, und für das Publikum schienen die Geschichten von den gierigen Frauen nichts prinzipiell Negatives zu enthalten.

Aus der Chronik erschließt sich ein weiter Bereich dessen, was als sozial akzeptiert angesehen wurde. Es fällt auf, dass Froben Christophs Sexgeschichten keinen sozialen Stand aussparen. Könige und Kaiser sind ebenso Gegenstand seiner Darstellungen, wie sämtliche Schichten des Adels und des Klerus bis hin zu Bürgern und Bauern. Obwohl Froben Christoph die Chronik im Zeitalter der Konfessionalisierung geschrieben hat, spielt Konfession bei der Darstellung der Sexualität keine Rolle. Der kaisertreue Graf kommt nie auf den Gedanken - wie es in späteren Zeiten üblich war -, gewisse sexuelle Praktiken denunziatorisch der anderen Konfession zuzuschreiben, wie er sich überhaupt für religiös-theologische Streitfragen gar nicht interessiert. Man könnte zugespitzt gera-

\footnotetext{
${ }^{9}$ JeNNY, Graf Froben Christoph von Zimmern, 190 u. 194.

${ }^{10}$ KUHN, Standesgenossen.

${ }^{11}$ HURWICH, Strategies 185.
}

dezu sagen: Sex ist für Froben Christoph enorm wichtig, Religion nicht.

Die Vorgehensweise im Folgenden ist einfach: Aus den zahlreichen Fällen der Chronik werden für die verschiedenen sozialen Stände exemplarisch einige herausgegriffen. Ständeübergreifend werden dann einige Phänomene näher dargestellt und die Befunde abschließend zusammengefasst. Dabei spielt es, es sei nochmals wiederholt, selbstverständlich keine Rolle, ob und inwieweit die einzelnen Geschichten „wahr" sind.

\section{Reden und zeigen}

Grundsätzlich sieht die Chronik der Grafen von Zimmern ihre Aufgabe nicht darin, einen Kata$\log \mathrm{zu}$ Normen und Grenzen des Sexualverhaltens aufzustellen. Auf den ersten Blick gibt es in der Chronik überhaupt wenige moralische Urteile und Vorschriften für das Sexualleben. Es dominiert eine voyeuristische, ironisch-hämische Grundeinstellung, die oft regelrecht in schenkelklopfende Heiterkeit übergeht.

Sexualität wird fast nie verurteilt, weder männliche noch weibliche. Geredet wird über Sex viel und drastisch, bemerkenswerterweise in allen Ständen, sowohl unter Bauern als auch unter Königen und Kaisern. Verbale Zurückhaltung gibt es da nicht.

So wird ohne jede Empörung eine Geschichte erzählt, die den König und späteren Kaiser Ferdinand (1503-1564) betrifft. Der sei unzufrieden gewesen, weil er nur Töchter und keinen Sohn gehabt habe. Da alle ärztliche Kunst versagt habe, habe Ferdinand schließlich den alten Koch seines Großvaters, Kaiser Maximilians (14591519), befragt, der geraten habe: „Allergnedigester künig, es ist ain schlechte kunst, so auch die pauren gemainlich und am bösten künden. Ewer Majestat besteig mein gnedigeste frawen, die künigin, alle nächt fünf oder sechs mal, so zweifelt mir nit, es werde doch etwan ein mal gerathen; da es aber die ein nacht nicht, so ge- 
rath es doch die andern." Die bei dieser Sexualberatung mit anwesende Königin habe sich darüber sehr amüsiert. ${ }^{12}$

Nicht einmal angeblich unersättliche Ehefrauen werden grundsätzlich missbilligt. Wenn ein Mann mit einer solchen verheiratet war, konnten zwar die gesundheitlichen Folgen für ihn wegen sexueller Überforderung fatal sein, aber so der Tenor der Chronik - so ist das Leben halt: Von den verschiedenen einschlägigen Beispielen seien nur zwei erwähnt: So habe Schenk Chri stoph von Limpurg "an seinem weib, dieser grefin von Werdenberg, sich abgeritten und der ehelichen werk so überflüssig gepraucht, das er zu keinen kreften mer komen und dessen entlichen hab sterben mueßen". Einige Jahre später habe auch Markgraf Johann von Brandenburg, "ein gar schoner, junger fürst“, dasselbe Schicksal gehabt, weil er den Bedürfnissen seiner Gemahlin, einer Gräfin von Foix, nicht gewachsen gewesen sei. ${ }^{13}$ Etwas anders gelagert war der Fall des Grafen Christoph von Werdenberg, der sich bei seinen außerehelichen Affären so verausgabt habe, dass er im Ehebett nichts mehr zustande gebracht habe und er deswegen kinderlos geblieben sei. Deshalb sei seine Familie ausgestorben. ${ }^{14}$ Abgesehen von dem selbstverständlich nicht überprüfbaren Wahrheitsgehalt dieser Geschichten, wird an den die Männer überfordernden Frauen eigentlich keine Kritik geübt.

${ }^{12} \mathrm{ChZ} 4$, 43. Im Falle Ferdinands ist die Chronik fern der Realität: Ferdinand und seine Frau Anna hatten elf Kinder, darunter vier Söhne, von denen zwei früh geboren waren (KOHLER, Ferdinand I. 99f.).

${ }^{13}$ ChZ 3, 57, 63f; KUHN, Standesgenossen 174. Es handelt sich um Markgraf Johann von BrandenburgAnsbach-Kulmbach (1493-1525), verheiratet mit Germaine von Foix. Für den unerwarteten Tod Johanns wurde gerüchteweise seine Ehefrau verantwortlich gemacht, die ihn - nach anderer Lesart als in der Chronik - nicht sexuell überfordert, sondern vergiftet haben soll. Vgl. zu Johann: HIRSCH, Johann (Markgraf von Brandenburg-Ansbach).

${ }^{14} \mathrm{ChZ} 3,47$.
Auch ein Mönch und seine Partnerin kommen im Urteil des Chronisten erstaunlich glimpflich weg. Der Mönch Bartholme Kobolt aus Salem, ein „wilder brueder“, soll anlässlich eines Schäferstündchens mit Katharina Hege tiefgründige Reden geführt haben. Die zwei gingen rasch zu konkreten Aktivitäten über: „do wardt dem münch $[\ldots]$ das eisen so hitzig, [...] das er sie gleich in der furia uf ain bank [...] legt und sie entblöst. Ehe und zuvor aber der scharrmitzel angieng, greift der münch mit baiden henden zum gaffeisen und sicht hienein“. Was er sah, erregte "grose begir", und er geriet in eine Art Delirium und war so "transi“", dass er philosophierte: „Hie sihe ich die ganzen welt und was darin ist". Aber obwohl er "gespannen [hatte] und gleich wolt abgeschossen haben", gediehen die Dinge nicht weiter. Als ein als Voyeur tätiger Hirte die beiden störte, habe der Mönch die "ufgehepte schenkel“ Katharinas „wider niederfallen und schnappen" lassen und sei zusammen mit Katharina geflohen. ${ }^{15}$

Am unteren Ende der sozialen Skala wird aus dem bäuerlichen Milieu von einem Bauernjungen und einem Mädchen berichtet, die einander näherkommen wollten. Der junge Bursche wusste nicht recht, wo hinein, das etwas erfahrenere Mädchen half ihm aber, den richtigen Eingang $\mathrm{zu}$ finden und feuerte den unerfahrenen Liebhaber an: „Hör nit bald auf, und fick mich!“ Die Geschichte sei öffentlich geworden, weil ein Vagant nahebei sein Nachtlager hatte und weitererzählte, was er gehört hatte. ${ }^{16}$

Von einem namentlich nicht genannten Domherrn aus Mainz wird berichtet, der habe "ain solliche unruhe in der bruech [Unterhose gehabt], das im der wadel in etlichen wochen weder tag oder nacht [...] nicht mocht gebogen oder geschwecht werden". An solchen Dauererektionen hätten auch zwei andere Männer

\footnotetext{
${ }^{15}$ ChZ 4, 7.

${ }^{16} \mathrm{ChZ} 3,310$.
} 
gelitten. Die Ärzte hätten das Übel mit Aderlässen kuriert. ${ }^{17}$

Überhaupt sind sexuell-medizinische Defekte ein beliebtes Thema der Chronik. Manchmal sprachen sogar Angehörige ganz unterschiedlicher Stände über Sexualprobleme miteinander, und gelegentlich blieb es nicht einmal beim bloß Verbalen, sondern ging in sehr visuelle Bereiche über. Das betraf dann nicht nur die beiden am Sex Beteiligten, wie im Falle Kobolts, sondern konnte auch Außenstehende betreffen: Als 1544 der Wild- und Rheingraf Jakob, Domherr in Straßburg, den 50. Jahrestag seiner Priesterweihe beging, er muss also schon vorgerückten Alters gewesen sein, hatte er "ein bösen dolchen". Hilflos, wie er war, präsentierte er seinen „bösen Dolch" seinen Bauern. Die meinten, Jakobs Annele sei die Ursache des „bösen Dolchs”. Es folgt eines der Wortspiele der Chronik: Jakob habe Annele mit "so groser müe entrainet" also "durchgezogen", "trainiert", "gefickt". Annele jedoch habe nicht nur bei ihm, sondern bei „etlichen herzögen alle leger durchschloffen gehapt“. Die Chronik fügt hinzu, dass die Krankheit, mit der Annele "begabet" gewesen sei und den "hausrath" Jakobs infiziert habe, nicht von den Herzögen, sondern von den „kuchenbueben und garköchen zu Straßburg" herrühre.

Gleich im Anschluss an den „bösen Dolch“ Jakobs schiebt der Chronist eine ähnliche Geschichte nach. Diesmal hatte ein Bauer aus der Grafschaft Wiesensteig einen "schaden“ wie der Wild- und Rheingraf. Der Bauer begab sich zu seiner Landesherrin, der Gräfin von Helfenstein, "und wolt ires raths pflegen“. Um sie ins Bild zu setzen, "nestelt er sich uf und wolt die hosen überabziehen". Die dann doch indignierte Gräfin erlaubte das nicht. Bestraft wurde der Bauer

${ }^{17}$ Ebd. wegen seiner sehr direkten Vorgehensweise aber nicht. ${ }^{18}$

Wenn es um Gespräche geht, werden auch Frauen keineswegs als züchtig errötende, schüchterne Wesen dargestellt, sondern zeigen sich der verbalen Drastik der Männer gewachsen. Das wird schon aus der bereits erwähnten Reaktion von König Ferdinands Gemahlin deutlich, die den Rat des alten Kochs, einfach nächtens mehr Sex zu haben, ausgesprochen lustig gefunden haben soll. Aber auch andere Frauen halten sich nicht zurück. Als um 1520 die auf einen Hirschplan bei Sigmaringen mitgenommenen Damen sahen, wie ein Hirsch eine Hirschkuh bestieg, stellten sie umgehend Vergleiche des Hirschpenis mit seinem menschlichen Gegenstück an und kamen zum Schluss, dass die Männer kaum etwas in der Unterhose (bruech) hätten und anders als die Hirsche auch "sonst nit ain starken zinken" vorweisen könnten. ${ }^{19}$ Und zwei junge adlige Damen, die vor dem Hofgericht in Rottweil anlässlich eines von ihnen abzulegenden Eides ihre Hand auf den hölzernen Richterstab legen sollten, dachten angesichts des Schwurstabes gleich an einen andern, eher organischen Stab und brachen derart in Gelächter aus, dass sie den hölzernen Stab gar nicht mehr anfassen konnten. ${ }^{20}$

\footnotetext{
${ }^{18}$ ChZ 3, 491. Solche Liebhaberinnen von Domherren soll es öfters gegeben haben. So soll Dorothea Grüninger aus Straßburg etliche adlige Liebhaber gehabt haben, zunächst den bereits erwähnten Wildund Rheingrafen Jakob, von dem sie mehrere Kinder bekommen habe. Dem Druck seiner Familie musste sie zwischendurch weichen, sie sei dann aber wieder zu ihm zurückgekehrt, bevor die Beziehung schließlich doch endete. Weitere Liebhaber Dorotheas seien die Domherren Eberhard von Eberstein und Hans Christoph von Zimmern gewesen. Sogar als Dorothea, alt geworden, als „ußgemergelts und abgerittens, ungetrewes, listigs pecus", beschrieben wird, scheint sie eine gewisse Faszination bewahrt zu haben (ChZ 2, 618, vgl. Hurwich, Strategies 201).

${ }^{19} \mathrm{ChZ} 3,60 \mathrm{f}$.

${ }^{20} \mathrm{ChZ} 3,532 \mathrm{f}$.
} 


\section{Frauen haben ein Recht auf Sex und Lust}

Unbestritten war, dass Frauen ein Recht auf Sex und auf Lust hatten. Das wird Frauen kategorisch zugebilligt. Männer mit erektiler Dysfunktion oder sonst impotente Männer galten deshalb als Problem. Aus den zahlreichen Beispielen seien nur wenige erwähnt:

Aus dem Jahre 1538 wird von einer jungen Frau berichtet, die viel von ihrem neu Angetrauten erwartet habe, denn er sei „ain junger gesell und starks leibs [...] auch starck under der gurtel" gewesen. Leider erwies sich, „er welt oder könt ir nichs gutes thuen“. Weder ein schwarzes Huhn, das man ihm in die Hand gegeben hatte, noch eine Wallfahrt halfen. Lendenschwache Männer wurden allgemein als „brueder Engele“ bezeichnet. Mancherorts habe der Verlobte sogar schwören müssen, dass er ein „hertbarer gesell" sei. Der doppeldeutige Ausdruck kann sowohl einen Mann bezeichnen, der einen Haushalt versorgen kann (Herd als pars pro toto), als auch einen Mann mit hartem Penis. Auf jeden Fall musste der Verlobte bestätigen, „das er wol hasplen künde uf der betziehen“. ${ }^{21}$

Aber Potenzprobleme kommen in allen sozialen Schichten vor. Als Dr. Lienhart Hochmüller, Richter am Reichskammergericht in Speyer, einen Termin mit einer Edelprostituierten ausgemacht hatte, habe er völlig versagt, denn er sei ein „gueter, alter knecht [gewesen...der] nit vil [...] mehr machen konnte “. ${ }^{22}$

Völlig enttäuscht war die Frau des Mesners von Rosenberg. Sie hatte eine Affäre mit dem Freiherren Jost Münch von Rosenberg. Bei einem seiner Besuche sei er völlig indisponiert gewesen, wollte sich aber rechtfertigen: „Wie kann

\footnotetext{
${ }^{21}$ ChZ 3, 202-205. Vgl. auch das Beispiel des zimmerschen Hofnarren Gabriel von Magenbuch, dessen Versagen bei einem Schäferstündchen genüsslich und ausführlich beschrieben wird (ChZ 1, 300).

${ }^{22}$ ChZ 1, 647.
}

ich meine fünf und sibenzig adern so baldt ufbringen, als du dein lere deschen?“ Die „leere Tasche" sei also bereit zu jeder Aktion gewesen, Josts „75 Adern” dagegen nicht. ${ }^{23}$

Froben Christoph bedauert sogar die Frau des fetten Grafen von Tengen. Die habe nur Ungemach mit solch einem Mann, mit dem sie keine Lust empfinden könne. Da der adipöse Graf nicht in der Lage gewesen sei, seine Frau zu befriedigen, ist der Chronist voller Verständnis, dass diese sich beim Schreiber des Grafen und beim Ofenheizer bediente. ${ }^{24}$

Wenn es kritische Kommentare über weiblichen Sex gibt, dann sind diese formelhaft und ohne erkennbares moralisches Engagement des Chronisten. Als sich Anna Hecker, die Frau des Marte Spindler, bei ihrer Mutter "mit wainenden augen $[\ldots]$ von wegen des übergroßen, ungefüegen hausraths" ihres Mannes Marte Spindler beklagte und denselben auch noch näher beschrieb, wirkt es angesichts des detaillierten Interesses, das der Länge von Martes Penis gilt, wie eine Art salvatorische Klausel, wenn dann knapp angefügt wird: „Hini zum teufel mit solchen unreinen leuten! Dann es contra bonos mores ist. “25

Zwei Töchter des Grafen Eitelfriedrich von Zollern, eine von ihnen seit 1539 verwitwet, teilten sich einvernehmlich den Ehemann der nicht verwitweten, den als Vogt tätigen Jakob Zimmerle. Die junge Witwe soll beim Ausritt mit ihrem Schwager, auf demselben Pferd sitzend, "mit der ainen hand sich an seinem poeniten-

\footnotetext{
${ }^{23} \mathrm{ChZ} 3,223$.

${ }^{24} \mathrm{ChZ} 3,76$.

${ }^{25}$ ChZ 2, 557-559; Martes Penis beschreibt Anna „mit ußgestrecktem arm [und zeigt] ain sollichs meß, das solchs aim mülleresel zu schaffen het geben“. Anna habe sich nicht vorstellen können, wie dieses Gerät in ihr Platz finden könnte und deshalb ihrer Mutter vorgeschlagen, sie solle doch an ihrer Stelle den Platz im Ehebett einnehmen. Die Mutter habe abgelehnt und gemeint, mit der Zeit würde sich Anna an das große Ding gewöhnen.
} 
zer", d.h. an seinem Penis festgehalten haben. Die Vorwürfe wurden so ernst genommen, dass die Familie Zollern um ihren Ruf fürchtete und eingriff. Die Witwe wurde regelrecht gekidnappt und auf dem Zollern inhaftiert, der Liebhaber selbst längere Zeit in Oberndorf eingesperrt. Zum Schicksal seiner Ehefrau, der illegitimen Zollerntochter, wusste man nichts weiter. ${ }^{26}$

Umgekehrt teilten sich auch zwei Männer eine Frau, nämlich die Grafen Felix und Christoph von Werdenberg eine gewisse Leonora. Die hatte ihren Mann, einen Kürschner, sitzen gelassen, um mit den beiden Grafen eine Dreierbeziehung anzufangen - sehr zum Leid von deren Ehefrauen: „Die eheweiber muesten das sehen, dem beiwonen und darzu schweigen, solt es innen gleich haben das herz abgestoßen." In der Verwandtschaft stieß die Dreierbeziehung auf heftige Ablehnung. Es wurde über die beiden gelästert, die beiden Grafen seien die verhurtesten Schwäger im Land. ${ }^{27}$

Insgesamt gibt es in der Chronik keine einheitliche Haltung zum weiblichen Sex. Einerseits werden Frauen als bloße Sexualobjekte dargestellt, die man nicht nach ihrer Zustimmung frägt, andererseits gibt es ausgesprochen selbstbestimmte Frauen, in deren Händen die Männer hilflos und weich wurden wie Wachs. Zwischen diesen beiden Extrempositionen - dominanter Mann mit unterwürfiger Frau und dominante Frau mit unterwürfigem Mann - finden sich die unterschiedlichsten Zwischenformen.

\footnotetext{
${ }^{26}$ ChZ 3, 405f; zur Affäre Zollern-Zimmerle: HURWICH, Strategies 190, mit falscher Quellenangabe. HuRWICH verweist auf ChZ 3, 482f, wo es um einen völlig anderen Sachverhalt geht.

${ }^{27}$ ChZ 2, 267; vgl. auch HuRWICH, Strategies 191.
}

\section{Keine moralischen Urteile, sondern Lästern, Spott und groteske Freizeitunterhaltung}

Im eingangs beschriebenen Falle Mechthilds wie auch sonst überwiegt in der Chronik das Interesse fürs Groteske, und moralische Ablehnung wird nur pro forma und nebenbei gezeigt. Über die Feststellung, Mechthild sei halt "fleischgierig" gewesen, geht die Kritik nicht hinaus. „Fleischgierige“ Frauen gab es nach Froben Christophs Vorstellungen eben. Grotesk ist auch die über Heinrich von Hannover und Maria von Württemberg erzählte Geschichte: Ein lauter Furz der Braut habe die Hochzeitsnacht unterbrochen. Heinrich beruhigte Maria: Das sei angesichts seines riesigen Instruments normal, das nur mit solchen Begleittönen Platz im Körper junger Damen finden könne. Überhaupt heißt es, alle Herzöge von Hannover seien überdurchschnittlich ausgestattet gewesen, und ihre Männlichkeit sei überdies darauf zurückzuführen, dass sie nicht zwei, sondern drei Hoden hätten. ${ }^{28}$

Charakteristisch für das Lästern ist die obszöne Geschichte rund um den polnischen König Sigmund (1467-1548). 1518 wurde Bona Sforza, Sigmunds zweite Ehefrau, von Italien nach Polen geholt. Unterwegs verbrachte ein listiger polnischer Adliger, der dem König ähnlich sah, einige Nächte in Bonas Bett. Als sie in Polen dann den echten König sah, war sie entsetzt, auf einen Schwindler hereingefallen zu sein. Sigmund selbst musste gute Miene zum bösen Spiel machen. Die Geschichte von Bona verbreitete sich in ganz Europa und ihr Ruf scheint, wie schmutzige Gedichte zeigen, völlig ruiniert gewesen zu sein:

„Regina Bona / Tria nobis attulit dona; / Faciem pictam, / Pecuniam fictam, / Vulvam haud valde strictam“ (Königin Bona, du bringst uns drei

${ }^{28}$ ChZ 2, 398. 
Geschenke: Eine bemaltes Gesicht - wie es der italienischen Mode entsprach -, Geld, das es nicht gibt und eine ausgeleierte Möse). Ein „welscher kämmerling“ aus Augsburg lieferte dazu sonst nirgendwo überlieferte Informationen über die Mode der Intimrasur in der Renaissancezeit und drückte dies in zwei unnachahmlichen Versen großer Literatur aus: „Et culum rasum / Tibi super nasum“ (Und sie hält ihren rasierten Arsch über deine Nase). ${ }^{29}$

Regelmäßig hat man den Eindruck - etwa beim „Beischlafen auf Glauben“, bei dem ein Gast ins Bett der Tochter des Hauses gelegt wird, aber diese nicht berühren darf -, dass sich der Chronist wesentlich mehr fürs Bizarre als für die Moral interessiert. ${ }^{30}$

Bizarr ist auch die Geschichte um den Grafen von Tengen, der so fett war, dass Kaiser Karl V. seinen Bauch nackt sehen wollte. Der Kaiser meinte, es sei völlig unmöglich, mit einem so gewaltigen Ranzen einer Frau beizuliegen. Aber Tengens Dienerin hatte eine Art Flaschenzug gebaut, damit der Graf sich seiner Frau nähern konnte. ${ }^{31}$

Größtes Vergnügen bei den Zuhörern muss auch ein Missgeschick des Hans Jakob von Landau hervorgerufen haben. Einige Familien des schwäbischen Adels hatten sich versammelt, um die Heiratspläne ihrer Söhne und Töchter zu besprechen. Während seine Eltern und die übrigen Adligen die Eheprojekte besprachen, war

${ }^{29} \mathrm{ChZ} 3,469 \mathrm{f}$.

${ }^{30} \mathrm{ChZ} 4$, 147; mit folgender Geschichte: Obwohl ein Gast versprochen hatte, die Tochter des Gastgebers in Ruhe zu lassen, begann er sie zu befingern. Die junge Dame verbat ihm kategorisch, tiefer als bis zu ihrem Gürtel zu gehen. Der Gast erhielt von einem in der Nähe schlafenden Mann, der wegen der nicht ganz geräuschlosen Intimitäten aufgewacht sei, den Rat, der Gast möge doch den Gürtel einfach bis zu den Knien des Mädchens hinab schieben, dann könne er oberhalb des Gürtels ja tun, was er wolle. Vgl. zum Beischlafen auf Glauben auch SCHERR, Deutsche Kultur- und Sittengeschichte.

${ }^{31} \mathrm{ChZ} 3,76$.
Hans Jakob in der direkt anschließenden Küche mit einer jungen Dame aktiv. Mangels eines Bettes, lehnten sich die beiden stehend gegen eine Tür. Da die nicht stabil war, fiel das Paar mitsamt der Tür um - genau in den Raum hinein, in dem die Adligen konferierten. Alle anwesenden Eltern waren keineswegs peinlich berührt, sondern brachen in Gelächter aus, verließen dann aber diskret den Raum, damit sich das Paar entflechten konnte. ${ }^{32}$

Tiefer gehende moralische Empörung ist rar. Sogar bei den zahlreich in der Chronik vorkommenden sexuell aktiven Nonnen klingt das scheinbare Verdammungsurteil (räudige Schafe) aufgesetzt, da im gleichen Atemzug vermerkt wird, es sei doch nur allzu verständlich, bei einer hübschen Nonne schwach zu werden. ${ }^{33}$

Aber wo sind die Grenzen? Was wird als unschicklich empfunden? Wo geht das Unschickliche in klare Ablehnung über? Wo beginnt sexuelles Handeln, das explizit als kriminell eingestuft wird?

Zunächst einmal ist festzustellen, dass es die Chronik bevorzugt, sexuelle Aktionen eher lächerlich zu machen und sich über Missgeschicke und Kuriositäten zu amüsieren. Sogar Geschlechtskrankheiten werden in der Chronik als kuriose Missgeschicke beschrieben, die eben vorkommen. Manchmal wird von Adeligen berichtet, die auf ihr Malheur geradezu stolz gewesen seien. Bei Froben Christophs Aufenthalt in Paris teilte dessen Freund Anton von Schauenburg ihm mit, dass er an einer Geschlechtskrankheit leide. Der Chronist differenziert: Es gebe zwei Arten von Pusteln (urslechten), nämlich große und kleine. Es sei alles gar nicht so schlimm, denn nicht jeder werde angesteckt, und im Übrigen werde in Frankreich

\footnotetext{
${ }^{32}$ ChZ 2, 197.

${ }^{33}$ ChZ 3, 315; vgl. auch die Geschichte aus dem Nonnenkloster Heiligkreuztal, ChZ 2, 640, dazu auch KUHN, Standesgenossen 175.
} 
niemand als Adliger anerkannt, der nicht die großen „urslechten“ habe. ${ }^{34}$

Lächerlich gemacht wird auch der Ehemann, der sich wegen der nicht mehr vorhandenen Jungfernschaft seiner Braut beklagte. Er bekam vom Straßburger Domkapitel den Bescheid, er solle sich wegen solcher Lappalien nicht aufregen. Damit wird freilich zugleich deutlich, dass fehlende Jungfernschaft der Braut zwar in der Theorie abgelehnt wurde, dass aber in der Praxis andere Maßstäbe galten. Besonders bemerkenswert ist die Feststellung des Domkapitels, dass solches ,"auch mechtig könig und fürsten leiden“ müssten, d. h. die Domherren gingen davon aus, dass es auch in höchsten Kreisen mit der Virginität der hohen Bräute nicht immer weit her war. ${ }^{35}$

Naivität sexueller Akteure wird auch im Zusammenhang mit der Jungfernschaft dem Spott preisgegeben: So habe eine künftige Schwiegermutter dem Bräutigam erläutert: Ihre zur Ehe anstehende Tochter habe die Jungfernschaft verloren, als der Arzt sie mit einem eisernen Instrument habe therapieren müssen. Der Chronist lästert, dass nur der Bräutigam diese Geschichte geglaubt habe. Alle andern hätten gewusst, es sei „kein eisern instrument, sonder der rechten lebendigen pessaria eins gewesen, welches [...] auch so vil gewürkt, das was lebendigs darauß worden“. In solchen Fällen versuchte man, die Jungfernschaft der Braut zu reparieren. Die Herren von Thurn hätten das mit einem jüdischen Arzt aus Frankfurt versucht, der dafür berühmt war, solch einen ,jungfrawenschaden“ beseitigen zu können. ${ }^{36}$

\footnotetext{
${ }^{34}$ ChZ 3, 254.

${ }^{35}$ ChZ 3, 473f. HuRwich, Strategies 191f., betont, dass zumindest in Adelsfamilien „female sexual behavior" von der Familie bestimmt worden sei. Wenn die Geschichte vom "nachtschaden“ stimmt, kann dies nicht sehr effektiv gewesen sein.

${ }^{36}$ ChZ 3, 474; KUHN, Standesgenossen 175.
}

\section{Grenzen der Akzeptanz}

Das erwähnte „Beischlafen auf Glauben“ stellt Froben Christoph durchaus missbilligend als etwas aus der Zeit Gefallenes dar, und er hält die Prozedur auch für moralisch indiskutabel, da damit viele Frauen, ohne es zu wollen, zu unzüchtigem Treiben verleitet würden.

Vollkommen normal sei es, dass ein Ehemann auch ein einfacher Müller - das Recht habe, gegen einen im Bett seiner Gemahlin angetroffenen Mann - und sei es auch ein Adliger - gewalttätig zu werden. Das galt sogar für Froben Christophs eigene Verwandtschaft: Als sein Onkel Gottfried Werner eine Nacht im Bett einer Müllerin verbrachte und der Müller nachts heimkam, war es die selbstverständlichste Sache der Welt, dass der Graf sich durch einen Sprung aus dem Fenster in Sicherheit bringen und unter dem Mühlrad verstecken musste, weil er von dem gehörnten Ehemann Übles fürchtete. Das Amüsement der Erzählung vergrößert sich noch dadurch, dass Gottfried Werner mitten im Winter nackt unter dem Mühlrad ausharren musste, „biß er frost und kelte halb schier erstarret". Er sei nur deshalb mit dem Leben davongekommen, weil der Müller die Suche eingestellt habe. ${ }^{37}$

Intensivere Missbilligung ist selten und verteilt sich auf alle sozialen Stände und auf beide Geschlechter. Wirklich tiefe Ablehnung ruft in der Chronik z.B. ein Akt von Fellatio hervor, bei dem eine Frau dem Mann beinahe den Penis abbeißt. Froben Christoph scheint hier wirklich schockiert gewesen zu sein und vermerkt, dass solche Frauen hart bestraft werden müssten. ${ }^{38}$ Gegenüber Klerikern, Weltgeistlichen, Mönchen und Nonnen, ist der Chronist dagegen meist ziemlich großzügig. Das Sexualleben diverser Personen geistlichen Standes wird ausgiebig

\footnotetext{
${ }^{37} \mathrm{ChZ} 2,484 \mathrm{f}$.

${ }^{38} \mathrm{ChZ} 2,286$.

${ }^{38} \mathrm{ChZ} 2,553$.
} 
und mit Interesse für das pikante Detail wiedergegeben. Davon nachfolgend nur eine kleine Auswahl:

In der Literatur des 15. und 16. Jahrhunderts haben Geistliche, namentlich Mönche und Nonnen, im Hinblick auf Sex einen extrem schlechten Ruf. Zwar ist anzunehmen, dass die Chronik spektakuläre Einzelbeispiele besonders herausstellt, aber letztlich bleibt unklar, wie viel Sex es tatsächlich hinter Kirchen- und Klostermauern gab. 39

Kompliziert war die Affäre zwischen Graf Eitelfriedrich von Zollern und der Nonne Barbara von Fridingen aus dem Kloster Heiligkreuztal. Der Graf habe Barbara entführt, sie aber, nach Abkühlen seiner Begeisterung, nach einiger Zeit wieder zurück ins Kloster gebracht, wo sie wahnsinnig geworden sei. Die Chronik bemerkt, die Entführung sei eigentlich ganz logisch gewesen: Wer hätte bei einer so schönen Nonne nicht ebenso gehandelt? Zudem sei sie ja kein Einzelfall, denn es gebe auch ,sonst mer der reudigen schaff im closter". ${ }^{40}$

Tatsächlich gibt es mehr Geschichten von „räudigen Schafen", so etwa im Kloster Oberndorf. Die 24 Nonnen - ,mertails alle vom adel“ - sollen nachts ohne Licht Tänze abgehalten haben, und es sei ein großes Amüsement gewesen, in der Dunkelheit einen unbekannten männlichen Partner zu finden, wenn es dabei auch Pannen geben konnte: Ein Besucher sei im Finstern an die falsche Partnerin geraten: "Ich habe mein schwester erwüschet!“41 Bei den nächtlichen Tänzen im Kloster scheint es sich zunächst einmal um eine der Übertreibungen des Chronisten zu handeln. Es gibt aber handfeste Beweise, dass so etwas tatsächlich vorgekommen ist - und beim Tänzchen blieb es dann nicht. ${ }^{42}$

\footnotetext{
${ }^{39}$ FRITZ, Lust im Kloster 10-13.

${ }^{40} \mathrm{ChZ} 3,315$.

${ }^{41}$ ChZ 2, 640; Kuhn, Standesgenossen 175.

${ }^{42}$ Die nächtlichen Tänze in Nonnenklöstern werden auch außerhalb der Chronik immer wieder erwähnt,
}

Nach einem Brand in einem Straßburger Nonnenkloster habe man in einem der Betten „ain mansperson [...] uf ainer closterfrawen im bet nackend" gefunden. Beide waren bei dem Brand erstickt. Es stellte sich heraus, dass mehrere junge Männer als Kinder ins Kloster gekommen waren. Die Nonnen hätten sie „,biß in ire manbare jar behalten und nach der haut [...] gebraucht". ${ }^{43}$

Ein Adliger aus dem Schwarzwald habe seiner Frau erlaubt, ihre Schwester im Kloster Kirchberg zu besuchen. Dort habe aber die hübsche junge Frau samt ihrer Schwester und anderen Nonnen gerne Herrenbesuch empfangen. Walter von Geroldseck und Oswald von Neuneck hätten zu ihrem Vergnügen in zwei Klosterzellen jeweils ,ain nackend weibsbild [...], ein hübsche, junge, zarte fraw" gefunden - die Frau des erwähnten Adligen und ihre Schwester. Froben Christoph betont, dass die junge Dame regelmäßig ins Kloster Kirchberg gekommen sei, „wann sie hungerig gewesen, [...] und hab iederweil ein spieß dulcedinis alda bekommen". Viele Jahre später habe der Geroldsecker die mittlerweile alt gewordene Adlige wieder getroffen. ${ }^{44}$

Ähnliche Geschichten über Sex im Kloster finden sich in der Chronik wiederholt, so u.a. die von Kaiser Maximilian, der das Kloster Lindau oft besucht habe - wegen „der schönen frawen darin". Nicht nur Maximilian selbst sei einschlägig tätig gewesen, sondern auch seine Schreiber, die ein "metzle“, also eine Hure, in ihren Schlafraum bestellt hätten. ${ }^{45}$ Sonderlich empört scheint der Chronist angesichts des angeblich so lustigen Treibens in den Klöstern nicht zu sein.

Einer der Mönche, der auch schriftstellerisch berühmte elsässische Franziskaner Thomas

\footnotetext{
sind also offenbar keineswegs Erfindungen von Froben Christoph; vgl. EHMER, Stift Oberstenfeld 137-140.

${ }^{43}$ ChZ 2, 640-642.

${ }^{44}$ ChZ 2, 643-647.

${ }^{45} \mathrm{ChZ}$ 4, 207.
} 
Murner (1475-1537), wird sogar als eine Art Potenz-Champion dargestellt, der es bei einer jungen Dame in Straßburg geschafft habe, ihr „innerhalb wenig stunden achzehen mal die flech zwischen [den] bainen helfen fahen". Damit verweist er andere Kerle mit endloser Manneskraft auf die hinteren Plätze. So soll der Bischof von Trient, Christoph von Madrutsch (1512-1578), in einer Nacht „nur“ 10 Mal seine Dame beglückt und sich dabei noch entschuldigt haben, er sei von der Reise müde, sonst hätte er es besser gemacht. Er wurde überboten von dem Elsässer Peter Hagenmann, der bei einem Besuch bei der Frau des Melchior von Masmünster $12 \mathrm{Mal}$ erfolgreich war. Dabei habe auch die als besonders lüstern beschriebene Dame mitgeholfen, deren Unersättlichkeit Peter beklagte, die er aber bewundernd beschreibt: "Sie war noch ganz jung und wundergail, das bedörft rugkenschmalz, wie man sprücht." 46

Andere Mönche kommen im Urteil Froben Christophs nicht so gut weg wie Thomas Murner, so etwa zwei Überlinger Bettelmönche, die Affären mit zwei Näherinnen hatten. Einer der beiden wurde vom Hausherrn mitsamt Näherin gleich die Treppe hinuntergeworfen, der andere konnte klugerweise rechtzeitig die Flucht ergreifen. Hier liegt einer der relativ wenigen Fälle vor, in denen Froben Christoph explizit moralisch verdammt. Solange die Mönche im Kloster gewesen seien, hätten sie sich an die Ordensregeln gehalten, sie hätten aber die Gelegenheit missbraucht, außerhalb des Klosters zu betteln. ${ }^{47}$ Bei einem weiteren Mönch ist der Chronist sogar regelrecht empört. Er schildert einen Fall, bei dem sich ein Franziskaner an eine Adlige habe heranmachen wollte. Der Mönch sei, vom Regen durchnässt, von der Dame in ihrem Haus aufgenommen und mit einem trockenen Hemd versorgt worden. Der Franziskaner verstand das

\footnotetext{
${ }^{46} \mathrm{ChZ} 2,647 \mathrm{f}$.

${ }^{47}$ ChZ 2, 562.
}

falsch und dachte, sie wolle ihn in ihr Bett holen. Er meinte, er fühle sich „wie ainer katzen; so man die selb über den rugken streicht, so heb sie den schwanz auf“. Die Adlige wies den Annäherungsversuch brüsk ab.

Ihrem heimgekehrten Ehemann erzählte die Frau, was vorgefallen war, woraufhin dieser den Mönch zu einem Fest einlud. Als der Mönch angekommen war, zwang ihn der Adlige, sich nackt auszuziehen: "do sahe man wol, das er kain münch, sonder ein hengst war." Der "Hengst" wurde gezwungen, in einen Zuber des wegen des Winters eiskalten Wassers zu steigen, so lange, bis ihm "die hitze und gaile [...] vergangen, $[\ldots]$ ", so dass ihm nicht mehr "wie der katzen $[. .$.$] der schwanz het ufgericht { }^{\prime \prime}{ }^{48}$

Die Geschichte scheint zu belegen, dass es mit der Sexualmoral der Mönche nicht weit her war. Aber die Geschichte mit dem Franziskaner stammt nicht aus Schwaben, sondern aus Köln. Sie wurde nur in die Zimmersche Chronik aufgenommen, um zu unterstreichen, dass der geile Mönch von weit her komme. Solche Mönche scheinen rar gewesen zu sein, denn aus Schwaben gab es keine passende Geschichte, sondern nur die eine aus Köln, die wegen ihrer Kuriosität in ganz Deutschland erzählt wurde.

Es gab also auch bei Klerikern Grenzen: Über einen Pfarrer, der in dauerhafter Beziehung mit einer Konkubine zusammenlebte, erregte man sich nicht, weil eine solche Verbindung offenbar weithin akzeptiert war, aber wenn ein Geistlicher hinter den verheirateten Frauen des Ortes her war, brachte dies die soziale Ordnung durcheinander. Hier lag eine inakzeptable, weil sozial gefährliche Grenzüberschreitung vor, die nicht nur verbale Missbilligung, sondern rabiate Maßnahmen erforderte. Noch glimpflich kam 1532 der Pfarrer von Oberndorf weg, der mit der Frau des Schuler-Jocole übereingekommen war, dass er "täglichs und wann er wolt, sein uftritt"

${ }^{48}$ ChZ 2, 637. 
bei der Dame haben dürfe. Als Jocole „den pfaffen ob dem weib [...] membra in membris" antraf, fesselte er den Geistlichen an allen Vieren und hängte ihn an einer Stange zum Fensterladen hinaus, wo er zum Gespött der Leute mehrere Stunden hängen gelassen wurde. Das Ehepaar versöhnte sich zum allgemeinen Erstaunen wieder, für den Pfarrer sah man das Aufhängen aus dem Fenster als ausreichende Strafe an.49

Heftiger traf es den Messkircher Kaplan Jörg („ein junger, starker bueb“), von dem berichtet wird, er habe es mit verschiedenen Ehefrauen getrieben. Deren Männer beschwerten sich direkt beim Grafen, der daraufhin dem Bader befahl, den Kaplan zu kastrieren. Der wurde allerdings vorher gewarnt und konnte - Penis und Hoden in guter Verfassung - rechtzeitig fliehen. ${ }^{50}$ Es handelte sich um keinen Messkircher Einzelfall und auch um kein Geflunker des Chronisten. Die Kastration von Geistlichen fand nicht selten statt, wenn es um deren Beziehungen zu verheirateten Frauen ging. Es gibt viele Beispiele dazu in den vatikanischen Akten. ${ }^{51}$

Erstaunlich neutral ist auch die Darstellung von Sex im Kloster im Besonderen oder von Sex bei Geistlichen im Allgemeinen. Oft ist die Tendenz die: So etwas passiert eben - auch in der erwähnten Geschichte Bartholme Kobolts wird der Mönch ja nicht eigentlich moralisch verdammt. Andererseits ist die Tendenz nicht eindeutig. Angefangen vom geradezu bewunderten Potenzprotz Murner bis zu deutlich kritisierten Klerikern findet sich alles. Über die erwähnten zwei außerhalb des Klosters allzu umtriebigen Überlinger Bettelmönche regt sich der Chronist durchaus auf, während im Fall des Kölner Fran-

\footnotetext{
${ }^{49} \mathrm{ChZ} 2,636 \mathrm{f}$.

${ }^{50} \mathrm{ChZ} 4,22$.

${ }^{51}$ Ludwig SchMUGge, Ehen vor Gericht 135-137. Zahlreiche Beispiele auch bei EsCH, Wahre Geschichten 33-42, und DERS., Lebenswelt 38-45; vgl. allgemein die Edition: SCHMUGGE Repertorium poenitentiariae.
}

ziskaners die Schadenfreude die moralische Missbilligung überwiegt. Weltgeistlichen, die hinter verheirateten Frauen her waren, geschah es dagegen - wie im Falle des Kaplans Jörg recht, wenn sie kastriert wurden. Hier war die Grenze der Akzeptanz klerikalen Sexualverhaltens endgültig überschritten.

\section{Härtere Sexualnormen für die Bevölkerung?}

So weit ging die Missbilligung sexueller Aktivitäten in der Chronik fast nie. Prostitution war lange Zeit vollkommen akzeptiert. Sogar in einer kleinen Stadt wie Messkirch gab es ein Frauenhaus. Etwa in den 1520er Jahren wurde dieses geschlossen. Den mit fliegender Fahne durchgeführten Auszug der örtlichen Huren schildert Froben Christoph als Kuriosität und ohne moralische Verdammung. Tatsächlich war aber die Exilierung der vorher in dem Städtchen geduldeten Huren durchaus ein Einschnitt, der zeitlich nicht zufällig ungefähr zeitgleich mit der Einführung des „lastersteins“ für die „normalen“ Messkircherinnen einherging. ${ }^{52}$ Der "lasterstein" war für Frauen eingeführt worden, die moralische Delikte, d.h. meist Verstöße gegen die sexuellen Normen begangen hatten. Vorher scheint man gegen derartige Verstöße großzügiger gewesen zu sein. So war es z.B. üblich, dass bei Prozessionen die Jungfrauen des Ortes vorangingen. 1508 störte man sich auf einmal daran, dass mehrere dieser angeblichen Jungfrauen erkennbar schwanger waren. Deshalb wurden nun die Jungfrauen von der Spitze des Prozessionszuges verbannt. ${ }^{53}$ Der "lasterstein“, mit dem man fortan unzüchtige Frauen bestrafte, war nicht ein Pranger im engeren Sinn, sondern ein Stein, den sie mit sich herumtragen mussten. ${ }^{54}$

\footnotetext{
${ }^{52}$ ChZ 3, 620-622, auch: HuRwICH, Strategies 205.

${ }^{53} \mathrm{ChZ} 2,178 \mathrm{f}$.

${ }^{54}$ ChZ 3, 620. Zum Pranger: LIDMAN, Spektakel.
} 
Insgesamt zeichnete sich in den ersten Jahrzehnten des 16. Jahrhunderts mit der Abschaffung des Frauenhauses, der neuen Platzierung der Jungfrauen im Prozessionszug und mit der Einführung des "lastersteins“ also durchaus ein nicht geringes Maß an Sanktionierung von Sexualdelikten ab. Die Prostitution, offenbar seit unvordenklichen Zeiten geduldet, wurde mit dem erzwungenen Auszug der Huren rabiat beendet. Bemerkenswert ist allerdings, dass die sexuellen Alltagsvergehen, die mit dem „lasterstein" geahndet wurden - mutmaßlich in der Hauptsache vorehelicher Sex -, den Chronisten im Einzelnen nicht weiter interessierten. Froben Christoph geht auf solche Alltagsvergehen, wenn nichts Außergewöhnliches und Kurioses vorlag, nicht näher ein.

Andererseits werden von ihm auch bürgerliche Frauen beschrieben, die in keiner Weise von schärferen Vorschriften beeindruckt waren: Als die Soldaten Kaiser Karls V. im Zuge des Schmalkaldischen Krieges Augsburg besetzten, hatten diese wegen ihrer sexuellen Übergriffe in der Bevölkerung einen extrem schlechten Ruf. Einer reichen Bürgerin sagte man aber nach, die Spanier ganz anders empfunden zu haben. Sie soll im Vergleich mit anderen Schleckereien gesagt haben: „ein spanischer schwanz übertref solche delicias alle mit ainandern!"

Nun ist der Begriff „Bevölkerung“ ziemlich diffus. Für die studierten Spitzen der nichtadligen Gesellschaft galten offenbar andere Normen als für einfache Bauern und Bürger. Insbesondere Studenten entzogen sich immer wieder den zunehmend strengeren Sexualnormen und werden als sexuell aktiv beschrieben. Im Fall der Ehefrau des Melchior Volmar (1497-156056) ist dies besonders originell, da Volmar als prominenter Luther-Anhänger und Professor an Bedeutung als moralische Instanz gewann, was

\footnotetext{
${ }^{55}$ ChZ 3, 311.

${ }^{56}$ ZELLER-LORENZ, Melchior Volmar Rot.
}

seine Studenten indessen nicht hinderte, ihn zu hintergehen. Von dem in Orléans, Bourges und später in Tübingen tätigen Volmar wird in der Chronik eine Episode aus seiner Zeit in Bourges erzählt: Seine sexuellen Fähigkeiten hätten nicht mit seinen intellektuellen Schritt halten können, weshalb man seiner Frau nachsagte, sich bei seinen Studenten bedient zu haben. Angeblich habe sie ihre Liebhaber mit einem Griff unter den Gürtel geprüft, und „es waren bei ir keine, als die mit eim langen elmeß angenem“. Einer der Studenten sei auch der Vater ihres Kindes gewesen - während der glückliche Volmar gedacht habe, es sei sein eigenes Kind. ${ }^{57}$

\section{Grenzen der Akzeptanz für Fürsten und Adel}

Grundsätzlich ist festzustellen, dass insbesondere bei Monarchen, bei Fürsten und im Adel ein erhebliches Maß an sexueller Betätigung der Akteure als normal angesehen wurde. Aber auch hier kam gelegentlich moralischer Tadel in der Berichterstattung vor. Das Treiben des französischen Königs Franz I. und seines Hofes wird deutlich missbilligt, das ganze Hofleben in Frankreich sei ein einziger "hurenhandel“, Franzens Übergriffigkeit gegen welche Frau auch immer, insbesondere gegen verheiratete Frauen, ging dem Chronisten erkennbar zu weit. 58 Als ungewöhnlich wird auch das zu Beginn beschriebene Verhalten der Erzherzogin Mechthild mit den ihr zugeschriebenen Affären vermerkt, freilich ohne Mechthild intensiver $\mathrm{zu}$ verdammen. „Fleischgierige" Frauen gab es nach Froben Christophs Vorstellungen eben. Der polnische König Sigmund wird dagegen wegen des Missgeschicks mit seiner Braut Bona Sforza, in deren Bett sich auf der Brautreise von Italien nach Polen der erwähnte, dem König ähnlich

\footnotetext{
${ }^{57}$ ChZ 3, 147.

${ }^{58}$ ChZ 3, 232f., 241f. u. 263-271.
} 
sehende Adliger geschmuggelt hatte, zwar gnadenlos und schadenfroh lächerlich gemacht, aber nicht im eigentlichen Sinne verurteilt.

Ähnlich waren die Gegebenheiten beim Adel allgemein. Man lachte, wenn der erwähnte sexuell rührige Jung-Adlige, der mit einer jungen Dame, an eine Tür gelehnt, stehend kopulierte, mitsamt Liebhaberin und wackliger Tür in den Versammlungssaal des schwäbischen Adels hineinfiel, ${ }^{59}$ aber man sah das Ganze als Missgeschick, nicht als etwas Verdammenswertes an. Nicht einmal die anwesenden Augenzeugen sollen sich empört gezeigt haben, sondern in Gelächter ausgebrochen sein. Missbilligt werden adlige Sex-Aktivitäten fast nie, solange sie kurz und dynastisch belanglos blieben. ${ }^{60}$

Bemerkenswert ist allerdings, dass mehrere in der Chronik genannte adlige Ehefrauen auch Gelegenheitsaffären ihrer Männer nicht ohne Weiteres duldeten, sondern mit lautstarkem Protest und sogar Ohrfeigen für den Täter reagierten oder die Konkurrentin aus dem Schloss hinauswarfen. ${ }^{61}$ Da ist es verständlich, dass es manchmal bei adligen Herren im Hinblick auf Beziehungen zu unverheirateten Mädchen oder Prostituierten durchaus ein intensives Gefühl der Peinlichkeit und Scham gab. Solche Affären wurden oft, zumindest zu Beginn, tunlichst geheim gehalten. Adlige wollten beim Sex nicht

${ }^{59} \mathrm{ChZ} 2,324$.

${ }^{60} \mathrm{ChZ} 2,197$.

${ }^{61} \mathrm{ChZ} 3$, 317, die Episode des Grafen Eitelfriedrich von Zollern, der eine Affäre mit der Nonne Barbara von Fridingen hatte. Als er irrtümlich nächtens seine Frau mit „Barbel“ ansprach, habe er umgehend von dieser eine Ohrfeige und die Klarstellung bekommen, sie heiße Johanna und nicht Barbel. Ebd. 315: Als die Ehefrau des Grafen Friedrich von Fürstenberg wegen einer Krankheit eine stinkende Salbe verwendete, quartierte sich der Graf bei einer Dienerin ein. Nachdem die Gemahlin realisierte, wo Friedrich steckte, beendete sie ihre Salbenkur, orderte ihren Mann zurück ins Ehebett, verlangte die Erfüllung seiner ehelichen Pflichten und setzte die Entlassung der Dienerin durch. Vgl. dazu auch HuRWICH, Noble Strategies 197. gestört werden und sie wollten sogar die sexuellen Aktivitäten als solche verbergen. Graf Georg von Bitsch wollte es vor seinen Reisegenossen verheimlichen, dass er in einer Herberge die Nacht mit einer "hipschen magt“ verbrachte (mit gutem Grund übrigens, denn als die Mitreisenden merkten, womit der Bitscher beschäftigt war, störten sie das Schäferstündchen umgehend und handgreiflich). ${ }^{62}$ Und Graf Gottfried von Zimmern versuchte sein Verhältnis zu Elsa Hartmännin, der sog. Faulhensin, peinlichst zu verbergen, ${ }^{63}$ ebenso auch Sixt von Hausen seine Beziehung zu einer gewissen Schellenfünfe. ${ }^{64}$

Bis weit ins 16. Jahrhundert hinein waren die Möglichkeiten der Kirche und des frühmodernen Staates bei der Durchsetzung von Sexualnormen begrenzt. Wichtiger als gesetzliche oder religiöse Vorschriften war der Einfluss der Familien. ${ }^{65}$ Bei den verschiedenen in der Chronik beschriebenen Affären zwischen adligen Männern und nichtadligen Mädchen muss oft echte Liebe und/oder sexuelle Faszination vorhanden gewesen sein. Manchmal blieben die adligen Herren dann unverheiratet und lebten mit ihrer Geliebten zusammen, manchmal - allerdings selten - heirateten sie sie sogar. ${ }^{66}$ Solch eine Heirat unter Rang war für die Verwandtschaft des Mannes die größte anzunehmende Katastrophe. In beiden Situationen - langes, eheähnliches Konkubinat oder gar formale Heirat - war diese strikt dagegen, und nicht selten waren die Familien erfolgreich, wenn sie versuchten, die Bezie-

\footnotetext{
${ }^{62} \mathrm{ChZ} 1,306 f$.

${ }^{63}$ ChZ 3, 308-310 u. 319.

${ }^{64} \mathrm{ChZ} 2$, 568f., vgl. die Missverständnisse von HuRWICH, Strategies 196, zum Spitznamen „Schellenfünfe".

${ }^{65}$ HURWICH, Strategies 175-192.

${ }^{66}$ Vgl. den Fall der Straßburgerin Dorothea, die eine langjährige Beziehung zu Wild- und Rheingraf Jakob, Domherrn in Straßburg hatte, ChZ 2 618, dazu auch. HuRwich, Strategies 201; oder die tragische Beziehung des Grafen Johann von Nassau mit „Leissa userm Niderlandt, ein rechts puppenmeiska", ChZ 3 442 .
} 
hung auseinanderzutreiben oder zumindest die Geliebte des Mannes zu enterben. In der Chronik wimmelt es von solchen Liebesbeziehungen, für die es im Adelsklatsch offenbar ein riesiges Interesse gab.

Wenn eine Geliebte begann, eine Ehe ernsthaft durcheinanderzubringen, wurden zudem die Ehefrauen extrem wütend, und deren Familien unterstützten ihre Töchter oder Schwestern gegen den untreuen Ehemann und seine Geliebte. ${ }^{67}$ Besonders erwähnenswert ist hier die Beziehung zwischen Gottfried Werner von Zimmern (1484-1554) und seiner Frau Appolonia, geborene von Henneberg. Sie verließ ihren Mann und kehrte zu ihrer Familie nach Franken zurück. Die Henneberger übten nun Druck auf die Zimmerer aus. Man legte vertraglich fest, dass die Gräfin wieder zu Gottfried Werner zurückkehren sollte. Dort angekommen, verlangte Appolonia eine Ehe ohne Sex, worauf Gottfried Werner nur allzu gerne einging. ${ }^{68} \mathrm{Ur}-$ sache der zerrütteten Ehe war die erwähnte Faulhensin. Ihr werden von dem sichtlich empörten Chronisten - es geht ja um seine eigene Familie! - die übelsten Charaktereigenschaften zugeschrieben: Um ihren eigenen Ehemann loszuwerden, habe sie die Nachricht verbreitet, er habe Sex mit Tieren. Faulhans, aus Angst, gevierteilt $\mathrm{zu}$ werden, habe deshalb fliehen müssen. Faulhensin, nun fest mit dem Grafen liiert, wurde von den Familien Zimmern und Henneberg als ",auspundt eines unverschampten weibs, schandtliche flaischgierige bestia" abgestempelt. ${ }^{69}$

Manchmal gelang es, die Ehestörerin zu isolieren und hinauszudrängen. Manchmal wurde der Ehemann gezwungen, seine Affäre zu beenden und sexuelle Beziehungen mit seiner Ehe-

\footnotetext{
${ }^{67} \mathrm{ChZ}$ 3, 308-310, 321. Vgl. auch den oben in Anm. 18 erwähnten Fall der Dorothea Grüninger aus Straßburg.

${ }^{68} \mathrm{ChZ} 3,324$.

${ }^{69}$ ChZ 3, 308-321.
}

frau wieder aufzunehmen. ${ }^{70}$ Aber zuweilen versagte aller dynastischer Druck, auch und sogar die Macht des Kaisers war begrenzt: Als sich Landgraf Wilhelm I. von Hessen (14601520) unter Verweis auf fehlende sexuelle Erregung beim Anblick seiner Frau Anna von Braunschweig, einer Tante von Kaiser Maximilian, weigerte, die eheliche Gemeinschaft mit dieser fortzusetzen, war nicht einmal der Kaiser in der Lage, etwas an der verfahrenen Ehe zu ändern. Wilhelm zeigte auf seinen Hosenlatz und meinte, dessen Inhalt "welle den beren nit stechen, er thue im gleich, wie er well“". Der Vergleich mit dem Bären, der nicht mehr gestochen werden könne, beeindruckte den Kaiser, der entgegen hielt: „Nun, nun, ich kan sein schwanz nit mandieren. ${ }^{\text {"71 }}$

Aber nicht nur Männer verweigerten erfolgreich den ehelichen Sex. Konrad von Bickenbach (+1486) soll vom desolaten Eheleben eines holländischen Grafen profitiert haben. Die Gräfin habe die Annäherungsversuche ihres Gatten stets mit dem Ausruf „Ayes paciens!“ abgewehrt. Das wurde auch ihr Spitzname. Soweit es Konrad betraf, war Geduld nicht nötig. Die Schöne sei ihm gegenüber äußerst willig gewesen. ${ }^{72}$

\section{Fazit}

Abschließend ist festzuhalten: Bei den zahlreichen Geschichten der Zimmerschen Chronik rund um das Thema Sex geht es in der Mehrzahl aller Fälle primär um Unterhaltung, um kurzweilige Geschichten, die der Adel sich beim geselligen Beisammensein erzählte. Insofern geht die in der Forschung gelegentlich und etwas abschätzig formulierte Aussage, das Erzählte sei ja alles gar nicht "wahr" oder zumindest „übertrieben“, an den Intentionen der Chronik

\footnotetext{
${ }^{70} \mathrm{ChZ} 3,324$.

${ }^{71}$ ChZ 3, 324-326.

${ }^{72} \mathrm{ChZ} 2,197$.
} 
vorbei. Dennoch ist der Realitätsgehalt der SexGeschichten der Chronik unterschiedlich: angefangen von der leicht erkennbaren Fiktion, über Fälle, bei denen man sich immerhin einen realen Kern vorstellen kann, bis hin zu Fällen, in denen dieser überwiegt. Diese verschiedenen Realitätsgrade herauszuarbeiten, war aber nicht die Absicht des vorliegenden Beitrags. Hier bleibt ein spannender Bereich für künftige Forschungen. Es ging vielmehr darum, herauszufinden, was nach den Vorstellungen des Chronisten erlaubt ist und was nicht. Grundsätzlich war ein hohes Maß an sexueller Toleranz vorhanden. Lust - männliche wie weibliche - sah man als gegeben und völlig legitim an. Frauen werden in der Chronik keineswegs als bloß untergeordnete Sex-Objekte dargestellt, sondern wirken in vielen Fällen erstaunlich gleichberechtigt und selbstbewusst: Ehefrauen schimpfen und ohrfeigen fremdgehende Ehemänner, und sie bedienen sich teils erfolgreich ihrer Familien, den Fremdgänger unter Druck $\mathrm{zu}$ setzen und $\mathrm{zu}$ disziplinieren. Manche Frauen halten sich ihre Ehemänner auch erfolgreich vom Leib und fordern sie ständig auf, Geduld zu haben. Andere fast durchwegs nichtadelige - Frauen gehen Langzeitbeziehungen mit adeligen oder sonst höhergestellten Männern ein. Hier greift der Mechanismus der Ausgrenzung dann besonders heftig. Solche Beziehungen stören (oder sprengen sogar) das Sozialgefüge und insbesondere die familiären Besitz- und Erbfragen. Entsprechend werden die Liebhaberinnen als Eindringlinge denunziert, beschimpft und oft verdrängt.

Insgesamt ist das Bild angesichts der etwa 200 einschlägigen Beispiele aber uneinheitlich und entsprechend bunt. Natürlich gibt es auch die Ehefrauen, die dem außerhäuslichen Treiben ihrer Ehemänner nicht ohrfeigend-selbstbewusst, sondern leidend zusehen müssen. Es kann jedenfalls keine Rede davon sein, dass die Seitensprünge der adligen Herren den adligen Damen gleichgültig waren. Andererseits schreibt die Chronik nicht wenigen Frauen auch ein nicht geringes Maß an sexueller Selbstbestimmung $\mathrm{zu}$, und wenn der Ehemann wegen Impotenz gar nicht oder wegen Fettleibigkeit nur unzureichend für „Kurzweil“ der Frau sorgen kann (so ein wiederholt verwendeter Ausdruck für die legitime weibliche Lust), dann zeigt die Chronik auch ein hohes Maß an Verständnis für Affären der Frauen. Die einzelnen Frauen unterstellte sexuelle Unersättlichkeit mag meist übertrieben sein, zumal sie ja insbesondere bei solchen sozial niedrig gestellten Frauen auftaucht, die durch ihre Affären die Kreise adliger Familien stören. Aber auch das lässt sich nicht verallgemeinern: Weibliche sexuelle Unersättlichkeit wird auch hochadligen Damen zugeschrieben - sei es, dass sie ihre Ehemänner sexuell überfordern und auf diese Weise ins Grab bringen, sei es - siehe das einleitende Beispiel der Erzherzogin Mechthild -, dass sie, angeblich selbstbewusst, in Abwesenheit des anscheinend unwilligen Ehemannes nach anderen Partnern suchen. Für die insgesamt selbstbewussten Frauen aus der Chronik böte sich künftig ein interkultureller Vergleich an: Wie werden Frauen dieser Zeit z.B. aus dem christlich-orthodoxen oder dem islamischen Bereich dargestellt?

Erstaunlich ist, dass die Chronik keinen sozialen Stand verschont und bis hinauf zu Königen und Kaisern Drastisches zu erzählen weiß. Es ist also keineswegs so wie in den antiken und in der frühen Neuzeit wieder belebten Theaterstücken, wo in der Tragödie nur das vornehmste und stets ernst genommene Personal auftritt, während in der Komödie die sozial tiefer gestellten Ränge mit ihren sexuellen „Deppengeschichten“ verlacht werden. Die Zimmersche Chronik verlacht eben auch und mit besonderem Vergnügen die Missgeschicke der ganz hohen Damen und Herren, und die Chronik missbilligt dann und wann auch deren Treiben, so etwa die Verhältnisse am französischen Königshof.

Angehörige des geistlichen Standes - Mönche, Nonnen und Weltkleriker - werden als oft sexu- 
ell höchst aktiv beschrieben. Die Darstellung geistlicher Bettgeschichten variiert in ihrer Bewertung: Auch hier findet sich häufig das nicht bewertende, sensationslüsterne Erzählen. Der kopulierende Bischof, der angeblich 18 Mal pro Nacht erfolgreiche elsässische Franziskanermönch, der Salemer Mönch, der mit der Brille die unterhalb der Gürtellinie gelegenen Schönheiten seiner Katharina inspiziert, der Kölner Mönch, bei dem die Auswirkungen von Eiswasser auf den Penis Interesse finden - das sind erkennbar in erster Linie unterhaltende Geschichten. Erstaunlicherweise kommt Missbilligung meist nur in homöopathischen Dosen vor, selten erfolgt eine explizite moralische Verurteilung, und wenn, dann hat man gelegentlich den Eindruck, diese Verurteilung sei eine eher formale Pflichtübung. So werden die angeblich sexuell sehr regen jungen Nonnen zwar als "räudige Schafe" beschrieben, aber deren Treiben doch letztlich als normal und verständlich dargestellt.

Mit der Ausweisung der Huren aus Messkirch und der Verbannung der angeblichen Jungfrauen von der Spitze der Prozessionen zeichnet sich - teilweise schon vor den reformatorischen Schriften Luthers - punktuell eine Verschärfung der Moralvorschriften ab. Die Chronik führt das jedoch nicht weiter aus. Das Interesse gilt nicht dem banalen vorehelichen Sex der Bevölkerung, und die diversen jungen Frauen, die sexuelle Beziehungen zu höhergestellten Männern haben, werden auch lange nach Luther offenbar von neuen Normen der Sexualmoral nicht erreicht.

\section{Korrespondenz:}

Prof. Dr. Gerhard FRITZ

Pädagogische Hochschule Schwäbisch Gmünd Institut für Gesellschaftswissenschaften Oberbettringer Straße 200 73525 Schwäbisch Gmünd Gerhard.Fritzph@gmuend.de ORCID-Nr. 0000-0003-2533-3453

\section{Abkürzungen:}

ChZ BARACK, Zimmerische Chronik Siehe auch das allgemeine Abkürzungsverzeichnis: [http://www.rechtsgeschichte.at/files/abk.pdf] 


\section{Literatur:}

Karl August BARACK (Hg.), Zimmerische Chronik, 4. Bde. (Freiburg-Tübingen 1881-1882).

KARL S. BADER, Die Zimmerische Chronik als Quelle rechtlicher Volkskunde (Freiburg 1942).

Hansmartin Decker-Hauff, Die Chronik der Grafen von Zimmern, 3 Bde. (Sigmaringen 1964-1972).

ERICA BASTRESS-DUKEHART, The Zimmern chronicle. Nobility, memory and self-representation in sixteenth-century Germany (Aldershot 2002).

CARL GEORG BONNEKAMP, Die Zimmerische Chronik als Quelle zur Geschichte des Strafrechts, der Strafgerichtsbarkeit und des Strafverfahrens in Schwaben im Ausgang des Mittelalters (Breslau 1940, ND Frankfurt am Main 1977).

Hermann EHMER, Stift Oberstenfeld (Ostfildern 2016).

Arnold EsCH, Wahre Geschichten aus dem Mittelalter. Kleine Schicksale selbst erzählt in Schreiben an den Papst (München 2010).

DERS., Die Lebenswelt des europäischen Spätmittelalters. Kleine Schicksale selbst erzählt in Schreiben an den Papst (München 2014).

Otto FrANKLIN, Die freien Herren und Grafen von Zimmern (Freiburg 1884).

Gerhard FRITZ, Geschichte der Sexualität von den Anfängen bis zur Gegenwart. Südwestdeutschland und seine Nachbargebiete (Ubstadt-Weiher 2016) 62-171.

Gerhard FRITZ, Lust im Kloster? Mythen und Quellen zur Sexualität im Mittelalter, in: Momente. Beiträge zur Landeskunde von Baden-Württemberg 4 (2016) 10-13.

Theodor HIRSCH, Johann (Markgraf von Brandenburg-Ansbach), in: ADB, Bd. 14 (Leipzig 1881).

Judith J. HuRwICH, Noble strategies. Marriage and sexuality in the Zimmern Chronicle (Kirksville 2006).

Alfred KoHLER, Ferdinand I. 1503-1564. Fürst, König und Kaiser (München 2003).

Elmar L. KUHN, Der Blick auf die Standesgenossen. Der schwäbische Adel im Spiegel der Zimmerschen Chronik, in: Casimir BumiLler, Bernhard RÜTH, Edwin Ernst WebER (Hgg.), Mäzene, Sammler, Chronisten. Die Grafen von Zimmern und die Kultur des schwäbischen Adels (Stuttgart 2012) 158-180.

Satu LIDMAN, Zum Spektakel und Abscheu. Schandund Ehrenstrafen als Mittel öffentlicher Disziplinierung in München um 1600 (=Strafrecht und
Rechtsphilosophie in Geschichte und Gegenwart 4, Frankfurt am Main u. a. 2008) 116-133.

Hans-Martin MAURER (Hg.), Eberhard und Mechthild. Untersuchungen zur Politik und Kultur im ausgehenden Mittelalter (= Lebendige Vergangenheit 17, Stuttgart 1994).

Dieter MERTENS, Die württembergischen Höfe in den Krisen von Dynastie und Land im 15. und frühen 16. Jahrhundert, in: Peter RÜCKERT (Hg.), Der württembergische Hof im 15. Jahrhundert (Stuttgart 2006) 75-98.

Carla MeYER, Im Schatten eines siegreichen Nachbarn? Die Württemberger und Friedrich I. von der Pfalz, in: Franz FucHS, Pirmin SPIEß (Hgg.), Friedrich der Siegreiche (1425-1476). Beiträge zur Erforschung eines spätmittelalterlichen Landesfürsten (Neustadt an der Weinstraße 2016) 141-174.

Konstantin Moritz A. LANGMAIER, Erzherzog Albrecht VI. von Österreich (1418-1463). Ein Fürst im Spannungsfeld von Dynastie, Regionen und Reich (=Forschungen zur Kaiser- und Papstgeschichte des Mittelalters 38, Köln-Weimar-Wien 2015).

Beat Rudolf JenNY, Graf Froben Christoph von Zimmern (Konstanz 1959).

Peter RÜCKERT (Hg.), Der württembergische Hof im 15. Jahrhundert (Stuttgart 2006).

Johannes SCHERR, Deutsche Kultur- und Sittengeschichte (Leipzig ${ }^{2} 1858$ ).

Ludwig Schmugge, Ehen vor Gericht. Paare der Renaissance vor dem Papst (Berlin 2008).

Ludwig ScHMUGGE u.a. (Hgg.), Repertorium poenitentiariae Germanicum, bisher 10 Bde. (Tübingen 1996-2016).

Tilmann WALTER, Unkeuschheit und Werk der Liebe, (Berlin-New York 1998).

Gerhard WOLF, Geschichtsschreibung ohne Territorium. Die Chronik der Grafen von Zimmern, in: Sönke LORENZ u.a. (Hgg.), Historiographie. Traditionsbildung, Identitätsstiftung und Raum (Ostfildern 2011) 75-94.

Gerhard WoLF, Von der Chronik zum Weltbuch. Sinn und Anspruch südwestdeutscher Hauschroniken am Ausgang des Mittelalters (Berlin-New York 2002).

Barbara ZELLER-LORENZ, Melchior Volmar Rot (14971560), in: Friedrich EbEL u.a. (Hgg.), Ferdinandina. Herrn Prof. Dr. iur. Ferdinand Elsener zum 60. Geburtstag am 19. April 1972 gewidmet von seinen Schülern (Tübingen ${ }^{21973) ~ 142-158 . ~}$ 